\title{
Addressing Load balancing Issues Related to Elastic Cloud Using Biomimetic Algorithms
}

\author{
Shahrzad Aslanzadeh, Zenon Chaczko \\ School of computing and Communication \\ Centre of Real Information Network \\ University of Technology, Sydney \\ Sydney, Australia \\ \{Shahrzad.aslanzadeh@uts.edu.au, \\ Zenon.Chaczko@uts.edu.au \}
}

\begin{abstract}
In business world, competitors use innovative approaches to improve their performance and profits. Cloud computing is one of these innovative approaches that have allowed many companies to further take advantage of their potential. Cloud computing is assisting companies to execute their business plans more efficiently, thus providing them with an advantage over their competitors.

Despite the benefits that cloud could offer, various challenges exist in this field. Load balancing and cloud performance are two examples of such challenges. This paper aims to discuss some of these challenges and how biomimetic algorithm could be employed to address them. Our approach is inspired by load regulation occurring in nature; more precisely, in human body.
\end{abstract}

Keywords - Cloud Computing, Load balancing, Biomimetic Algorithm

\section{INTRODUCTION}

Rapid improvement in today's technologies enabled businesses to grow more quickly. Cloud computing as one of the new emerging technologies, provides real time services for enterprises, without binding them to their organizations [1]. Accessing to the Internet with any devices that can connect to the Internet, authorized businesses to access their information at any time [2]. As an example, Dropbox is one of these popular services that will accredit access to information while it can be easily synchronized and updated at any time.

By applying the virtualization techniques, cloud providers can minimize the costs of resource management process [3].

As demonstrated by other researchers, cloud users can pay fees to access multiple resources at any time, especially in their peak hours, which will help them to grow more quickly and stand out among their competitors [4].

The next section will debate on some challenges associated within cloud computing, applied in businesses.

\section{DeBATABLE ISSUES IN ClOUd COMPUTING}

\section{A. Resource Availability}

The ambition of businesses is to give efficient services to their clients; this fact will only be applicable if their resources can be available all the times.
As mentioned above, cloud computing will bring the opportunity of handling shared resources, which will reduce the associated costs and expenses. Gupta [2] mentioned that there is no need to estimate how many recourses will be required upon forming the business. Also as cloud is offering on demand resources, they can easily add more nodes to their networks, which will clarify the meaning of scalability in businesses [1]. Brynjolfsson, et al [5], however; argued that although scalability will enable the businesses to add more resources to fulfill their requirements, it does not guarantee that more resources would result in more services. Availability of the resources will allow the businesses to deliver right services to satisfy their customers, which will add more credits to their reputation as well.

Chunlan et al[6] uses the water and electricity resources of a country as an example to elaborate on the "availability" concept in cloud computing. Occasional outages can result in interruption of supplied water or electricity to the residents. Likewise, recourses provided by cloud computing, cannot be completely relied upon, as technical issues may cause unavailability of such resources. In 2009, Amazon lost the availability of the its resources for about 6 hours, which caused the customers to suffer from that issue even after two days [4]. Moreover, problems with networks and Internet connections can affect resource availability of the cloud, which will result in losing accessibility to the information [7]. The solution given by different authors is mainly focused on service level agreement. Dillon [8] pointed out that signing the SLA, cloud providers would be responsible to guarantee their resources availability. As Habib [9] discusses there is, however, no special standard for documenting theSLAs. Also, lack of information that businesses have regarding their down time tolerance created many challenges by fading the importance of SLA. Therefore, organizing the SLA, by reviewing and mentioning different features of availability, will enable the businesses to increase the percentage of available resources and guarantee delivery of services to their clients at any time.

\section{B. Performance and Bandwidth Requirements}

Critical to the usage of services in cloud computing, bandwidth is playing a major role in facilitating the access to different applications [10]. Bandwidth requirement is essential 
in gaining the most benefits from cloud computing, whether using cloud for opening a simple email or using other services delivered by cloud providers. Brynjolfsson [5] mentions that bandwidth requirement is the fundamental point of supporting performance of the cloud. Yi [10], however, argues that the high price associated with bandwidth made the companies close their eyes on this important point and deliver services with acute latency to unsatisfied customers. Dahbur [11] discussed that most of the cloud providers want to deliver the services with low price, but with high performance. Neglecting the idea of using the shared resources, especially in peak hours of usage, will cause the customers experience a poor performance within the delivered services. Therefore, [1] suggests that to minimize the bandwidth costs, data management to adjust the data accessibility should be considered. Also, Gupta [2] notices that the network optimization in both cloud providers and cloud users is essential. An optimized Internet pipeline will help the cloud users to access their relevant application with high performance.

\section{III.ADDRESSING THE CHALLENGE OF LOAD BALANCING}

According to the literature discussed in previous sections, the main cause of challenges in cloud computing is related to load balancing techniques.

Several algorithms have been proposed so far addressing various issues of the load balancing in the cloud. In our research, we are proposing a new algorithm, inspired by the nature, focusing on biomimetic algorithms.

Tanya [12] believes that nature is a great encyclopedia for technology. Most of the clever technologies were inspired by the nature. The objective is to indicate the possibilities offered by a bio-inspired design approach in the solution of many technological issues. Designing the simple velcore is inspired by the plant bars attached to the dog's hair. The idea of lights reflection technology in LCD TVs originated from the design of butterfly wings. Similarly, this research is trying to model the solutions that nature provides for the issues; also known as biomimetic.

Endocrine algorithm and Spring Tensor Model are proposed as the biomimetic solution for solving the load balancing issues in cloud computing

\section{A) Endocrine algorithm}

- Endocrine glands are playing an important role in functionality of the endocrine systems. Hormonal regulation is managed by endocrine glands. Different algorithms have been proposed to explain the hormonal communication in human's body. But most of them are highlighting the feedbacking method, as the main communication process of hormones. "Figure 1" is depicting the hormonal reactions in endocrine systems. The motivation of this research is to model the regulation process of these hormones, based on their communication.

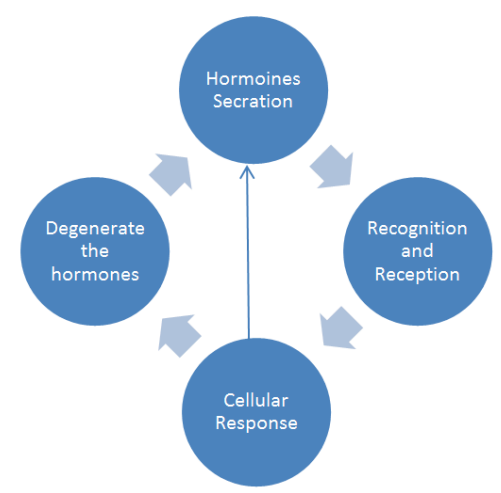

Figure 1- Endocrine feed backing procedure

\section{B. Spring Tensor Algorithm}

Spring Tensor algorithm emphasizes on predicting the direction and magnitude of the data load on each network nodes. This model will be adopted to plan, monitor (meter), manage and mitigate usage of the cloud computing resources and services seen as an elastic network (mass-sprin $\backslash \mathrm{g}$ model) made of nodes that are connected to its spatial neighbors by springs that are in constant interactions/motion (Fig. 2). The proposed approach should be seen in the context of barriers to cloud computing and as a search for better tools that can help to alleviate problems with network bandwidth and its elasticity. The main aim is to set potential research directions in the design of effective service and of resource usage monitoring technologies.

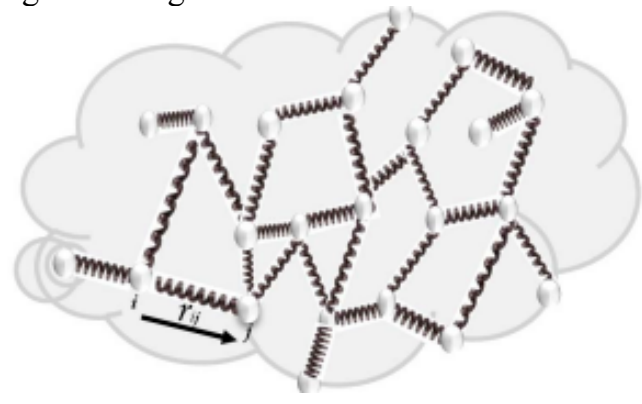

Figure 2-The model represent the elastic network. The relation between each resource is modelled with $r$. The spring tensor model will predict the direction and magnitude of the load on the network.

\section{CONCLUSION}

The above discussed factors, determined load balancing as one of the inhibitors which needed to be addressed in future of cloud computing. Two different algorithm have been proposed as a solution of enhancing the load balancing techniques in cloud. The expected benefits of the technique are attributed to the fact that every resource (node) of the cloud can adjust its operation according to the current situation in its neighborhood, rather than strictly following some predefined topologies and data routing algorithms. 


\section{REFERENCES}

[1] Creeger, M. 2009, CTO Roundtable: Cloud Computing, Communications of the ACM, Vol. 52, No. 8, pp. 50-56.

[2] Gupta, A. Cloud computing growing interest and related concerns. Computer Technology and Development (ICCTD), 2010 2nd International Conference on, 2-4 Nov. 2010 2010. pp. 462-465.

[3] Chunlan, L. \& Zhonghua, D. Value of Cloud Computing by the View of Information Resources. Network Computing and Information Security (NCIS), 2011 International Conference on, 14-15 May 2011 2011.pp. 108-112.

[4] Biocic, B., Tomic, D. \& Ogrizovic, D. Economics of the cloud computing. MIPRO, 2011 Proceedings of the 34th International Convention, 23-27 May 2011, pp. 1438-1442.

[5] Brynjolfsson, E., Hofmann, P. \& Jordan, J. 2010. Cloud computing and electricity: beyond the utility model. Commun. ACM, vol.53, pp.32-34.

[6] Chunlan, L. \& Zhonghua, D. Value of Cloud Computing by the View of Information Resources. Network Computing and Information Security (NCIS), 2011 International Conference on, 14-15 May 2011 2011.pp. 108-112.

[7] Takabi, H., Joshi, J. B. D. \& Ahn, G. 2010. Security and Privacy Challenges in Cloud Computing Environments. Security \& Privacy, IEEE, 8, pp. 24-31.

[8] Dillon, T., Chen, W. \& Chang, E. Cloud Computing: Issues and Challenges. Advanced Information Networking and Applications (AINA), 2010 24th IEEE International Conference on, 20-23 April 2010 2010. Pp.27-33.

[9] Habib, S. M., Ries, S. \& Muhlhauser, M. Cloud Computing Landscape and Research Challenges Regarding Trust and Reputation. Ubiquitous Intelligence \& Computing and 7th International Conference on Autonomic \& Trusted Computing (UIC/ATC), 2010 7th International Conference on, 26-29 Oct. 2010 2010. pp. 410-415.

[10] YI, W. \& Blake, M. B. 2010. Service-Oriented Computing and Cloud Computing: Challenges and Opportunities. Internet Computing, IEEE, 14, pp. $72-75$.

[11] Dahbur, K., Mohammad, B. \& Tarakji, A. B. 2011. A survey of risks, threats and vulnerabilities in cloud computing. Proceedings of the 2011 International Conference on Intelligent Semantic Web-Services and Applications. Amman, Jordan: ACM,pp.1-6

[12] Tanya Lewis, Biomimicry: 7 Clever Technologies Inspired by Nature ,22 April 2013 Time http://www.livescience.com/28873-cooltechnologies-inspired-by-nature.html 